\title{
Role of Lipase Activators Produced by Saccharomycopsis lipolytica and Calcium Ion in Its Lipase Reaction ${ }^{\dagger}$
}

\author{
Komakazu Gomi, ${ }^{\dagger \dagger}$ Yasuhide Ota ${ }^{* \dagger \dagger \dagger}$ and Yasuji Minoda \\ Department of Agricultural Chemistry, Faculty of Agriculture, \\ The University of Tokyo, Bunkyo-ku, Tokyo 113, Japan \\ * Department of Applied Biochemistry, Faculty of Applied Biological Science, \\ Hiroshima University, Fukuyama, Hiroshima 720, Japan
}

Received April 24, 1986

\begin{abstract}
Lipase activator activated the reaction by Saccharomycopsis lipolytica lipase at neutral $\mathrm{pH}$ in the presence of calcium ions, and $5 \mu \mathrm{g}$ of the activators were sufficient to cause the reaction to proceed at maximum activity in the presence of $2 \mu \mathrm{l}$ of tributyrin and 0.4 units of the lipase in a total volume of $360 \mu$ l.

To define the roles of the activator and calcium ion, we studied interactions between the activator and the lipase, between the activator and a hydrophobic interface, and between the lipase and the interface. Results suggest that the interfacial adsorption of the lipase is the limiting process of lipolysis and that it is controlled by the activator and by the concentration of calcium ions.
\end{abstract}

The lipases from Saccharomycopsis lipolytica are unique, because one extracellular lipase $^{1 \sim 4)}$ and two cell-bound lipases ${ }^{5)}$ of the yeast require amphiphilic lipase activators for their reaction, when they are purified enough. That is, the purified lipase never hydrolyzed purified substrate without the activator.

We have isolated three types of lipase activators $(\alpha, \beta, \gamma)$ from the culture broth of $S$. lipolytica and the main component of $\beta$ was identified with 3,5-dihydroxy-7-tetradecenoic acid. ${ }^{6}$ The free carboxyl group in this compound was essential for the activation of the lipase reaction.

In this paper we describe the roles of the lipase activator and calcium ion in lipolysis by $S$. lipolytica lipase and discuss their similarities to the roles of bile acids or colipase (a peptide) in lipolysis by the pancreatic lipase of mammals. $^{7)}$

\section{MATERIALS AND METHODS}

Chemicals. Olive oil was purchased from Iwaki Pharmaceutical Co.; yeast extract from Difco Laboratories; Sephadex LH-20 and Sephadex G-50 from Pharmacia Fine Chemicals; Nucleosil $5 \mathrm{C}_{18}$ from Macherey Nagel GMBH \& Co., KG; and glass beads coated with silicone gum SE30 from Nishio Kogyo Co.

Microorganism. The Saccharomycopsis lipolytica used was the strain deposited in CBS (No. 6303), ATCC (No. 48436), and IFO (No. 10073). This strain was isolated by one of us from soil in $1963 .{ }^{8)}$

Cultivation of S. lipolytica. The yeast was cultivated in a jar fermentor with an aeration rate of $0.6 \mathrm{vvm}$ and an agitation rate of $300 \mathrm{rpm}$ at $30^{\circ} \mathrm{C}$ for about $12 \mathrm{hr}$. The culture medium was composed of $2.0 \%$ glucose, $0.2 \%$ urea, $0.6 \% \mathrm{KH}_{2} \mathrm{PO}_{4}, 0.2 \% \mathrm{~K}_{2} \mathrm{HPO}_{4}, 0.1 \% \mathrm{KCl}, 0.05 \%$ $\mathrm{MgSO}_{4} \cdot 7 \mathrm{H}_{2} \mathrm{O}, 0.001 \% \mathrm{FeCl}_{3} \cdot 6 \mathrm{H}_{2} \mathrm{O}, 0.1 \%$ yeast extract, and $1.0 \%$ olive oil ( $\mathrm{pH}$ 6.2). The cultivated cells were collected by continuous centrifugation and washed with $0.85 \% \mathrm{NaCl}$ solution. The washed cells were stored at $5^{\circ} \mathrm{C}$ until use for purification of cell-bound lipases. On the other hand, the supernatant of the culture was concen-

${ }^{\dagger}$ This work was supported by a Grant-in-Aid for Scientific Research (No. 57360006) from the Ministry of Education, Science and Culture of Japan.

${ }^{+\dagger}$ Present address: Technical Research Laboratory, Asahi Chemical Industry Co., Ltd., 2-1 Samejima, Fuji, Shizuoka 416, Japan.

${ }^{\dagger \dagger}$ To whom all the correspondence should be addressed. 
trated to one tenth under a vacuum to extract lipase activators.

Purification of Lipase I. S. lipolytica produces Lipase I and Lipase II as cell-bound lipases under these conditions. In this study Lipase I was used and purified by the method described previously. ${ }^{5)}$ The purified lipase did not show any activity whithout lipase activator, as reported.

Isolation of Activators $\alpha, \beta$ and $\gamma$. Three kinds of lipase activators were extracted from the concentrated culture supernatant with ethyl ether at $\mathrm{pH} 2.0$ and separated from each other by our reported procedures. ${ }^{6}$ Activator $\beta$ was further purified by chromatography on Sephadex LH-20 (solvent, methanol) and by high performance liquid chromatography on a reversed phase column (Nucleosil $5 \mathrm{C}_{18} ;$ solvent, methanol-water-acetic acid $=60: 40: 0.2$ $\rightarrow 100 \%$ methanol).

Assay of lipase. Lipase I activity was measured by the shake method, as described previously. ${ }^{2}$ ) The reaction mixture was composed of $2 \mathrm{ml}$ of buffer $(0.2 \mathrm{M}$ Tris acid maleate $-0.2 \mathrm{M} \mathrm{NaOH}, \mathrm{pH} 8.2$ ), $1 \mathrm{ml}$ of $0.03 \mathrm{M} \mathrm{CaCl}_{2}$ solution, $5 \mathrm{ml}$ of deionized water, $1 \mathrm{ml}$ of olive oil, and $1 \mathrm{ml}$ of enzyme solution. The reaction mixture was incubated in a Monod tube at $37^{\circ} \mathrm{C}$ for $50 \mathrm{~min}$ with constant shaking (60 times/min). At the end of the reaction, $20 \mathrm{ml}$ of a $1: 1$ mixture of acetone and ethanol was added and the amount of liberated fatty acid was titrated with $0.05 \mathrm{~N}$ aqueous $\mathrm{NaOH}$. One unit of lipase was defined as the amount of enzyme which was able to liberate $1 \mu$ eq of acid per min under the conditions used. Pure Lipase I had a specific activity of 11,300 units $/ \mathrm{mg} \cdot$ protein.

Activation experiment by lipase activator and calcium ions. This experiment was done by a shake method on a microscale, as described in the previous paper. ${ }^{6}$ ) Two microliters of tributyrin, $5 \mu \mathrm{g}$ of the activator dissolved in $0.4 \mu \mathrm{l}$ of methanol, $80 \mu \mathrm{l}$ of buffer $(0.2 \mathrm{M}$ Tris acid maleate- $0.2 \mathrm{M} \mathrm{NaOH}, \mathrm{pH} 7.0$ ), $40 \mu$ l of $0.03 \mathrm{M} \mathrm{CaCl}_{2}$ solution, and $200 \mu \mathrm{l}$ of deionized water were mixed in a small glass tube $(8 \times 50 \mathrm{~mm})$. After preheating of the mixture at $37^{\circ} \mathrm{C}$ for $5 \mathrm{~min}, 40 \mu \mathrm{l}$ of purified Lipase I (10 units/ $\mathrm{ml}$ ) was added and shaken lengthwise 180 times/min for $50 \mathrm{~min}$. At the end of the reaction, $400 \mu \mathrm{l}$ of solvent (benzene-isopropanol-2.4 $\mathrm{N} \mathrm{HCl}=60: 40: 2$ by volume) was added to the reaction mixture and shaken vigorously to stop the reaction and to extract the product, butyric acid. After centrifugation $(3,000 \times g, 5 \mathrm{~min})$, the butyric acid in the solvent phase was measured by gas chromatography. ${ }^{6)}$

Sephadex G-50 chromatography of a mixture of Lipase I and Activator $\beta$. A column $(2 \times 60 \mathrm{~cm})$ of Sephadex G-50 was equilibrated with a medium of 2 parts of $0.2 \mathrm{M}$ Tris acid maleate- $-0.2 \mathrm{M} \mathrm{NaOH}$ buffer ( $\mathrm{pH} 7.0$ ), 6 parts of deionized water, and a part of $0.03 \mathrm{M} \mathrm{CaCl}_{2}$ solution. Then a mixture of Lipase I and Activator $\beta$ was put on the column and eluted with the same medium at a flow rate of $35 \mathrm{ml} / \mathrm{hr}$. The effluent was monitored spectrophotometrically at $280 \mathrm{~nm}$.

Adsorption of Activator $\beta$ on glass beads coated with silicone gum $S E$-30. A certain weight of the glass beads was introduced into a tube $(8 \times 50 \mathrm{~mm})$ and $50 \mu \mathrm{g}$ of Activator $\beta$ dissolved in $4 \mu \mathrm{l}$ of methanol was added. After the methanol was evaporated under a nitrogen stream, $1 \mathrm{ml}$ of the medium used in Sephadex G-50 chromatography was added and shaken vigorously for $1 \mathrm{~min}$. The mixture was centrifuged at $3,000 \times g$ for $5 \mathrm{~min}$ and absorbance of the supernatant was measured at $210 \mathrm{~nm}$ to estimate the amount of the activator.

Adsorption of Lipase I on glass beads coated with silicone gum $S E-30$. The procedures of this experiment were similar to those mentioned above. Ten milligrams of the glass beads were used and addition of Activator $\beta$ was $50 \mu \mathrm{g}$. Calcium chloride solution was replaced by deionized water, when testing with a deficiency of calcium ions. The residual lipase in the supernatant was measured by assay of its lipase activity using olive oil as substrate.

\section{RESULTS}

\section{Effects of reaction $p H$ on the activation with} Activators $\alpha, \beta$ and $\gamma$

Figure 1 shows the effects of $\mathrm{pH}$ on the tributyrin hydrolysis catalyzed by Lipase. I, when a sufficient amount of Activators $\alpha, \beta$, and $\gamma(5 \mu \mathrm{g})$ was added to the reaction mixture. All the lipase activators activated the heter-

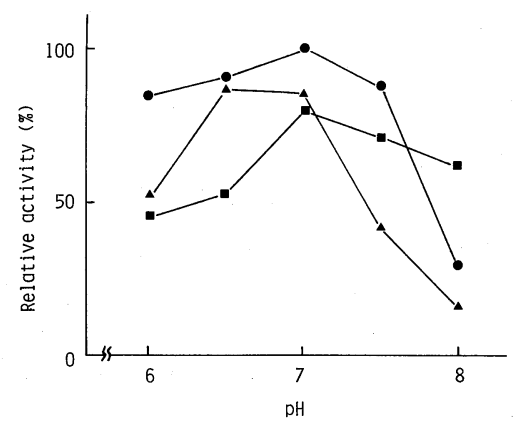

FIG. 1. Effects of $\mathrm{pH}$ on the Activation with Lipase Activators.

The experiment was done with shaking on a microscale, as described in the text (lipase amount 0.4 units), except that buffer of the indicated $\mathrm{pH}$ was used.

$\square$, Activ
Activator $\gamma$. 
ogenous system best at neutral $\mathrm{pH}$, agreeing with the earlier results obtained with Activator A. ${ }^{9)}$

\section{Activation curve with Activator $\beta$}

As shown in Fig. 2, tributyrin hydrolysis was activated with Activator $\beta$ according to a sigmoid curve. The activator did not show its activity at a concentration below $0.7 \mu \mathrm{g} /$ tube and an almost full activity was attained at a concentration of $5 \mu \mathrm{g} /$ tube. Similar results were obtained for Activators $\alpha$ and $\gamma$, but these findings are somewhat different from that described previously. ${ }^{9)}$

Requirement of calcium ions for the activation

The lipase reaction did not start even in the

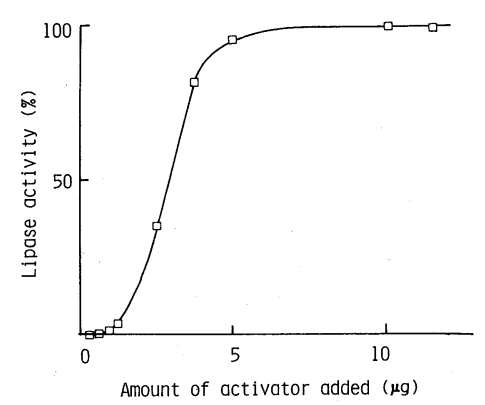

FIg. 2. Activation Curve with Activator $\beta$.

The experiment was done at $\mathrm{pH} 7.0$ as described in the text (lipase amount 0.4 units), except that indicated amounts of Activator $\beta$ were added.

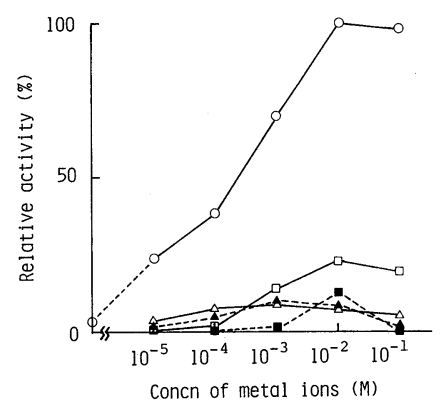

FIG. 3. Requirement of Metal Ions for Activation.

The experiment was done at $\mathrm{pH} 7.0 \mathrm{using} 5 \mu \mathrm{g}$ of Activator $\beta$ and 0.4 units of Lipase I.

$\bigcirc-\mathrm{O}, \mathrm{CaCl}_{2} ; \triangle-\triangle, \mathrm{MgCl}_{2} ; \square-\square, \mathrm{BaCl}_{2} ; \mathbf{\Delta}--\mathbf{\Delta}$, $\mathrm{KCl} ; \mathbf{- - -}, \mathrm{AlCl}_{2}$. presence of substrate and lipase activator. Figure 3 shows the activation with cations, especially with calcium ions; the maximal lipase activity was attained at $0.01 \mathrm{M}$ calcium chloride. Barium ions had a slight effect on the lipase reaction and these results coincide with those obtained with crude lipase activator $\left.{ }^{9}\right)$ and with oleic acid used instead of Activators. ${ }^{2)}$ It is concluded that the lipase from $S$. lipolytica requires the lipase activator and calcium ions to catalyze the hydrolysis of triglyceride and so on.

\section{Sephadex G-50 chromatography of a mixture of} Lipase I and lipase activator

A mixture of Lipase I (700 units) and Activator $\beta(500 \mu \mathrm{g})$ dissolved in $1 \mathrm{ml}$ of the medium described in Materials and Methods was put on a Sephadex G-50 column and eluted with the same medium. A chromatogram is given in Fig. 4. The lipase was eluted at void volume, the activator following it. The eluted lipase fraction showed a lipase activity of $16 \%$ under the standard assay conditions without further addition of the activator. On the other hand, the activator was not detected in the void volume if the lipase was not present. We concluded that the activator was adsorbed on the lipase and activated the lipase reaction in the reaction mixture. We estimated that about $0.11 \mu \mathrm{g}$ of Activator $\beta$ was adsorbed on 1 unit of Lipase I.

Similar results were obtaind in the absence

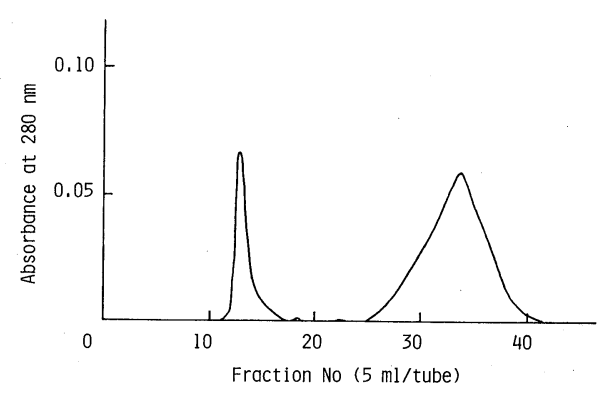

FIG. 4. Sephadex G-50 Chromatography of a Mixture of Lipase I and Lipase Activator.

Lipase I (700 units) and Activator $\beta(500 \mu \mathrm{g})$ dissolved in the medium described in the text were put on a Sephadex G-50 column and eluted with the same medium. 
of calcium ions and we suggested that calcium ions were not necessary to form the lipaselipase activator complex.

Adsorption of Activator $\beta$ on glass beads coated with silicone gum SE-30

Activator $\beta$ is a mixture of amphiphilic compounds. ${ }^{6)}$ Therefore, it is assumed that these compounds have a strong tendency to gather on the interface between insoluble

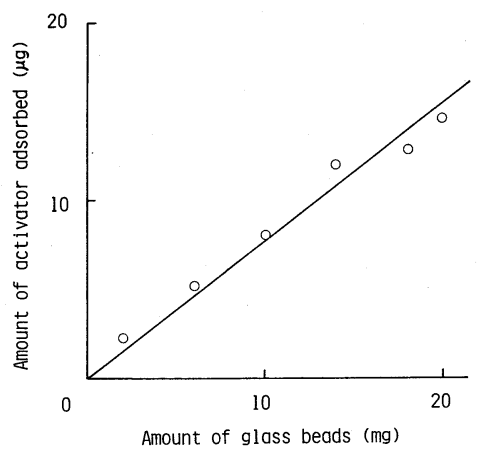

Fig. 5. Adsorption of Activator $\beta$ on Silicone-coated Glass Beads.

Small glass beads $(80 \sim 100$ mesh) were coated with silicone gum SE-30. Activator $\beta$ was adsorbed at $\mathrm{pH} 7.0$ in the presence of $0.03 \mathrm{M} \mathrm{CaCl}_{2}$.

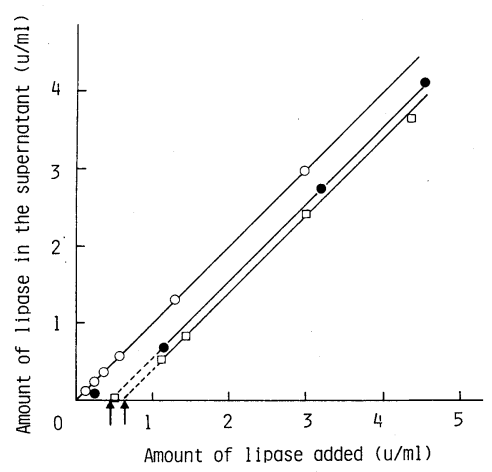

Fig. 6. Adsorption of Lipase I on Silicone-coated Glass Beads.

Ten milligrams of the glass beads and $50 \mu \mathrm{g}$ of Activator $\beta$ were used in each experiment. The final concentration of $\mathrm{CaCl}_{2}$ was about $3.3 \mathrm{~mm}$.

$\square-\square$, without both Activator $\beta$ and $\mathrm{CaCl}_{2} ; \bigcirc-\bigcirc$, with Activator $\beta$ and without $\mathrm{CaCl}_{2} ;-$, with both Activator $\beta$ and $\mathrm{CaCl}_{2}$.

Arrows indicate the intercept of each straight line on the axis of abscissa. substrates such as tributyrin and the bulky water phase. We selected small glass beads $(80 \sim 100$ mesh) coated with silicone gum SE-30 as analogous particles to the triglyceride emulsion, because they had a stable and hydrophobic interface.

Figure 5 shows the adsorption of Activator $\beta$ on silicone-cóated glass beads. The activator was adsorbed on the hydrophobic interface at a rate of about $0.8 \mu \mathrm{g}$ per mg of glass beads.

\section{Adsorption of Lipase I on glass beads coated with silicone gum SE-30}

1) Experiment in the absence of lipase activator and calcium ions. Only Lipase I and glass beads coated with silicone were added to Tris acid maleate buffer and the mixture was shaken well. After centrifugation the residual lipase in the supernatant was measured. Then the amounts of the lipase added and the lipase in the supernatant were plotted on the graph as shown in Fig. 6 and a straight line was obtained, which had a slope of $45^{\circ}$ and did not pass through the origin of the graph. The intercept on the axis of abscissa means the amount of lipase adsorbed on the glass beads. It is concluded that the lipase can be adsorbed on the hydrophobic interface in the absence of the activator and calcium ions.

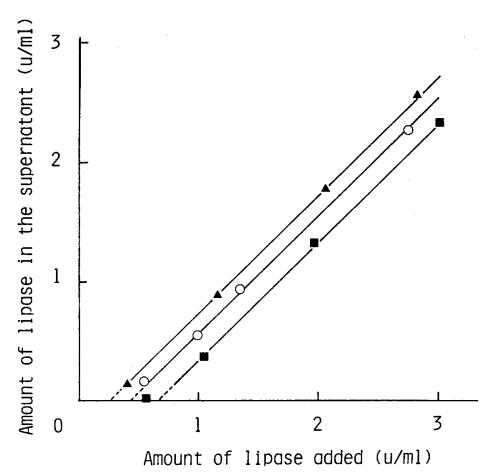

FIG. 7. Effects of Calcium Ion Concentration on Adsorption of Lipase I.

Interfacial adsorption was tested at $\mathrm{pH} 7.0$ in the presence of Activator $\beta(50 \mu \mathrm{g})$.

$\Delta-\boldsymbol{\Delta}, 10^{-4} \mathrm{M} \mathrm{CaCl}_{2} ; \bigcirc-\bigcirc, 10^{-3} \mathrm{M} \mathrm{CaCl}_{2}$; $10^{-2} \mathrm{M} \mathrm{CaCl}_{2}$. 
2) Experiment in the presence of the activator only. When the activator was present in the buffer, the graph gave also a straight line, which did not intercept the axis, but passed through the origin exactly (Fig. 6). This means that the lipase was not adsorbed at all on the interface modified by Activator $\beta$.

3) Experiment in the presence of both cofactors. As shown in Fig. 6, the lipase was adsorbed on the interface modified by the activator in the presence of calcium ions. Figure 7 shows that the amount of lipase adsorbed on glass beads increased, as the concentration of calcium ions was raised in the water phase.

\section{DISCUSSION}

The lipases from $S$. lipolytica required the lipase activator synthesized by the yeast itself and calcium ions to maintain their catalytic action (Figs. 2 and 3). The purpose of this study is to outline the role of these two cofactors, connecting with the interface existing between the insoluble substrate of lipase and the water phase.

It was supposed that the lipases would associate with lipase activator, because the lipases in the living yeast cells were active without addition of any lipase activator. ${ }^{10)}$ Unpublished data indicates that the activator bound on the enzyme was dissociated grad-

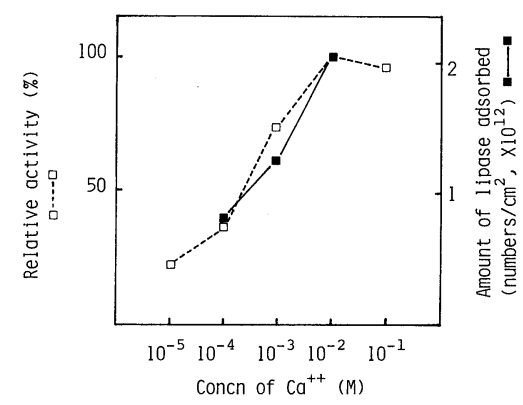

FIG. 8. Relation between Concentration of Calcium Chloride and Amount of Lipase I Adsorbed.

The amount of Lipase I adsorbed on silicone-coated glass beads was calculated from the data shown in Fig. 7. Relative lipase activity was obtained by experiments similar to Fig. 3. ually throughout the enzyme purification. The result shown in Fig. 4 confirmed this interaction between the enzyme and the activator.

The lipase activator (Activator $\beta$ ) had both hydrophobic and hydrophilic groups in the molecule ${ }^{6}$ and, therefore, it was assumed that this compound would be adsorbed on the oilwater interface and that, as a result, it could emulsify oily substrates in water. In this study we used silicone-coated glass beads to give a stable, inert interface. The experiment shown in Fig. 5 indicates the adsorption of the activator onto the hydrophobic silicone surface.

The lipase from $S$. lipolytica is the only one example of the lipase that cannot hydrolyze triglycerides in the absence of cofactor. We considered at first that the lipase could not be adsorbed on the hydrophobic interface of the substrate without the aid of an anionic and amphiphilic cofactor; however, this possibility is excluded from the experimental results, as shown in Fig. 6 ( $\square$ ). Therefore, the next problem is why the enzyme can not act on a pure interface after adsorption. Is the active site of the enzyme not induced or is the enzyme denatured by interfacial tension?

We also excluded from another finding (Fig. $6(\bigcirc))$ the possibility that the lipase activator assists in the interfacial adsorption of the enzyme. In the presence of the activator the lipase was not adsorbed at all, if calcium ions were not also present.

Calcium ions were very important for the enzyme adsorption. About 0.44 units of the lipase were adsorbed on $10 \mathrm{mg}$ of siliconecoated glass beads when $0.03 \mathrm{M}$ calcium chloride was present (Fig. 6). The area occupied by one molecule of the lipase is calculated to be $7,500 \AA^{2}$, assuming that the specific gravity of the glass beads is $2.08 \mathrm{~g} / \mathrm{ml}$. The area calculated from the data obtained in Fig. 7 is $11,200,8,500$, and $4,800 \AA^{2} /$ molecule, when $10^{-4}, 10^{-3}$, and $10^{-2} \mathrm{M}$ of calcium chloride was added in the water phase, respectively. Figure 8 illustrates the relationship between the concentration of calcium chloride and the amount of lipase adsorbed on the interface, and it can be seen that the curve obtained 
nearly coincides with the activation curve shown in Fig. 3 for calcium chloride. This suggests that the enzyme adsorption to oilwater interfaces is the limiting process, and it is controlled by the concentration of calcium ions.

Lipases from mammals such as pancreatic lipase, lipoprotein lipase, and hormone-sensitive lipase are activated by various kinds of cofactors. For porcine pancreatic lipase, bile salts and colipase are known as cofactors and their role in lipolysis was reviewed recently by Sémériva and Desnuelle. ${ }^{7)}$ The pancreatic lipase can be adsorbed on and hydrolyze triglyceride in the absence of cofactors, whereas the lipase of $S$. lipolytica can be adsorbed on, but can not hydrolyze triglyceride in the absence of cofactors. The pancreatic lipase cannot be adsorbed on a hydrophilic interface when it is covered with a bile salt such as sodium taurocholate. If colipase is present together with bile salt, colipase allows the lipase to be adsorbed on the interface and to react with the substrate. This phenomenon is very similar to that discussed with respect to the lipase of S. lipolytica; bile salt and colipase correspond to the lipase activator and calcium ion respectively. It is interesting to compare yeast lipase with pancreatic lipase in the hydrolysis of insoluble substrates.

\section{REFERENCES}

1) Y. Ota and K. Yamada, Agric. Biol. Chem., 30, 1030 (1966).

2) Y. Ota and K. Yamada, Agric. Biol. Chem., 30, 1030 (1966).

3) Y. Ota and K. Yamada, Agric. Biol. Chem., 31, 809 (1967).

4) Y. Ota, T. Nakamiya and K. Yamada, Agric. Biol. Chem., 34, 1368 (1970).

5) Y. Ota, K. Gomi, S. Kato, T. Sugiura and Y. Minoda, Agric. Biol. Chem., 46, 2885 (1982).

6) K. Gomi, Y. Ota and Y. Minoda, Agric. Biol. Chem., 50, 2525 (1986).

7) M. Sémériva and P. Denuelle, Adv. in Enzymol., 48, 319 (1979).

8) K. Yamada and Y. Ota, Nippon Nôgeikagaku Kaishi, 37, 649 (1963).

9) Y. Ota, K. Yoshioka, Y. Minoda and K. Yamada, Agric. Biol. Chem., 37, 2879 (1973).

10) T. Sugiura, Y. Ota and K. Yamada, Agric. Biol. Chem., 40, 2479 (1976). 